\section{Rediscovering and conserving endangered trees}

One of the main values of publishing global red lists of threatened species is to stimulate conservation action at both national and local levels. The World List of Threatened Trees (Oldfield et al., 1998) identified nearly 8000 globally threatened tree species, information which has subsequently been incorporated into the 2000 IUCN Red List of Threatened Species (Hilton-Taylor, 2000). In 1999, FFI contacted 120 of the botanists and foresters who compiled the information on threatened tree species around the world to find out if and how the tree conservation status information was being used. The questionnaire survey was undertaken as part of the planning process for the FFI/UNEP-WCMC Global Trees Campaign, which aims to save the world's most threatened tree species and their habitats through information provision, conservation and wise use.

From the 38 responses it is apparent that the information in the World List of Threatened Trees has already been used to stimulate a range of conservation actions. These include the designation and management of national parks in Bolivia, Mozambique and the Philippines, ex situ conservation planning for tree species in botanic gardens and arboreta around the world, project development in Ethiopia, Kenya and Central America, updating species legislation, the development of national and regional biodiversity databases, and field research.

Within The World List of Threatened Trees, Malaysia is recorded as the country with the highest number of globally threatened tree species. This partially reflects the richness of the tree flora and the natural rarity of many tropical forest species. It also reflects the level of knowledge and expertise in tree species identification within the country. Many other countries, which may have a greater number of threatened tree species, do not yet have the capacity to identify and record these. The Forestry Department of Peninsular Malaysia is taking The World List of Threatened Trees as a basis for review and conservation action. Resources are being sought to carry out this major task and initial work has already proved encouraging. Shorea kuantanensis, a dipterocarp, is recorded in The World List of Threatened Trees as Critically Endangered because the one locality in Kuantan, where the species was discovered, has now been converted into a plantation'. Recently the Forestry Department has found individuals which appear to be of the same species in forest reserves close to the original locality. Confirmation of the identity of the species by experts at the Forest Research Institute Malaysia (FRIM) will take place as soon as flowers and fruits are available. Specimens of Dipterocarpus sarawakensis another 'single location species' - have also been rediscovered in Peninsular Malaysia and await verification by FRIM.

Other dipterocarp species such as Dipterocarpus costulatus, D. grandiflorus, D. kerii, D. lowii, D. verrucosus, Shorea balanocarpoides and S. faguetiana, classified as Critically Endangered or Endangered based on global rates of decline, have been found to be relatively secure in Peninsular Malaysia. Initial indications from the Third National Inventory plots suggest that these species are relatively well distributed in both unlogged forests and in logged forests 11-30 years after logging. This type of detailed information will be invaluable to ensure effective species conservation planning within the Permanent Forest Estate.

Action to verify the conservation status of oak species in Mexico through detailed field survey has also been stimulated by the publication of The World List of Threatened Trees. A project supported by FFI's 100\% Fund, and led by Dr Maricela Rodriguez Acosta, suggested that the IUCN Red List category for Quercus hintonii should be changed from Critically Endangered to Endangered (unpublished report to FFI's 100\% Fund). A conservation and education strategy has been drawn up for this species and similar work is planned for the 30 other threatened or insufficiently known Mexican oak species.

Many of the species included in The World List of Threatened Trees are known only from a handful of localities. Many of these localities have not been revisited by botanists in recent years and there is great scope for a programme of tree species rediscovery. At the same time, with only 12 per cent of globally threatened tree species recorded in protected areas, and only 8 per cent known to be in cultivation, there is an urgent need for increased tree conservation action. The Global Trees Campaign is promoting such action and welcomes news of successful tree species rediscoveries and recovery activities around the world.

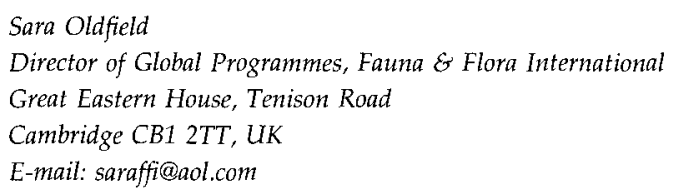




\section{References}

Hilton-Taylor, C. (compiler) (2000) 2000 IUCN Red List of Threatened Species. IUCN, Gland, Switzerland and Cambridge, UK.
Oldfield, S., Lusty, C. \& MacKinven, A. (compilers) (1998) The World List of Threatened Trees. World Conservation Press, Cambridge, UK. 